\title{
Simulation and Field Measurements of Reliability Parameters of Dump Truck Hydraulic System
}

\author{
Aleksey Khoreshok ${ }^{1, *}$, Andrey Kuznetsov ${ }^{2}$, and Anton Shalkov ${ }^{2}$ \\ ${ }^{1}$ T.F. Gorbachev Kuzbass State Technical University, Department of Mining Machines and \\ Complexes, 650000 Kemerovo, Vesennya st. 28, Kemerovo, Russia \\ ${ }^{2}$ Prokopievsk branch of T. F. Gorbachev Kuzbass State Technical University, Department of \\ Information Technology, Engineering and Motor Transport, 653039 Prokopievsk, Nogradskaya st. \\ 19a, Prokopievsk, Russia
}

\begin{abstract}
Paper studies the problem of non-failure operation of dump trucks hydraulic system that is exploited in the climatic conditions of Kuzbass region. The main characteristic of the Kuzbass climate is hardly continental, so, it has sharp fluctuations in ambient temperature for seasons, for a month or even a day. To analyze the negative factors affecting the operation of the dump trucks hydraulic system a systematic approach was used, based on the methodology of SADT structural analysis. The result of field and cameral researches identified that the major negative factor is instability of kinematic viscosity of working fluids used in the hydraulic system of mining dump trucks over a wide range of ambient temperatures. There were offered the further ways for methods to stabilize the parameters of working fluids in the hydraulic system of dump trucks.
\end{abstract}

\section{Introduction}

At present the open-mines method is mainly used for coal mining in Kuzbass. When transporting rock masses and minerals, dump trucks are used. In the conditions of the continental climate of the Kemerovo region, the dump trucks operates in a wide range of ambient temperatures. It affects negatively on the reliability of the dump trucks systems, particulary, on the hydraulic steering system and the platform lift-lowering system.

\section{Materials and Methods}

One of the main elements of the hydraulic systems of a dump truck is a gear wheel pump, intended for a working fluid's supplying to the actuators of the steering and the mechanism of platform lift-lowering system. These pumps are exposed to various factors: climatic conditions, intensity of operation, quality of maintenance, etc. Complex influence of the whole variety of factors evaluation is problematic. Therefore, to predict the reliability of the dump trucks hydraulic system it is necessary to use a systematic approach to describing the

\footnotetext{
* Corresponding author: haa.omit@kuzstu.ru
} 
problem, i.e. to present the problem in the form of an information system of knowledge and regularities.

To determine the requirements for the system and its functions, and then to develop a system that corresponds to the specified requirements and performs the specified functions, the methodology of structural analysis "SADT" (Structured Analysis \& Design Technique) was used. The IDEF0 and IDEF3 mixed methodology conforms to this task [1, 3, 6-8].

The "Gear wheel pump efficiency supporting in operational process" is the highest-order function in this structural model. For this function the main interactions (shown as arrows) are defined and described. The interactions activates the basic function of the structural model, as shown in Figure 1.

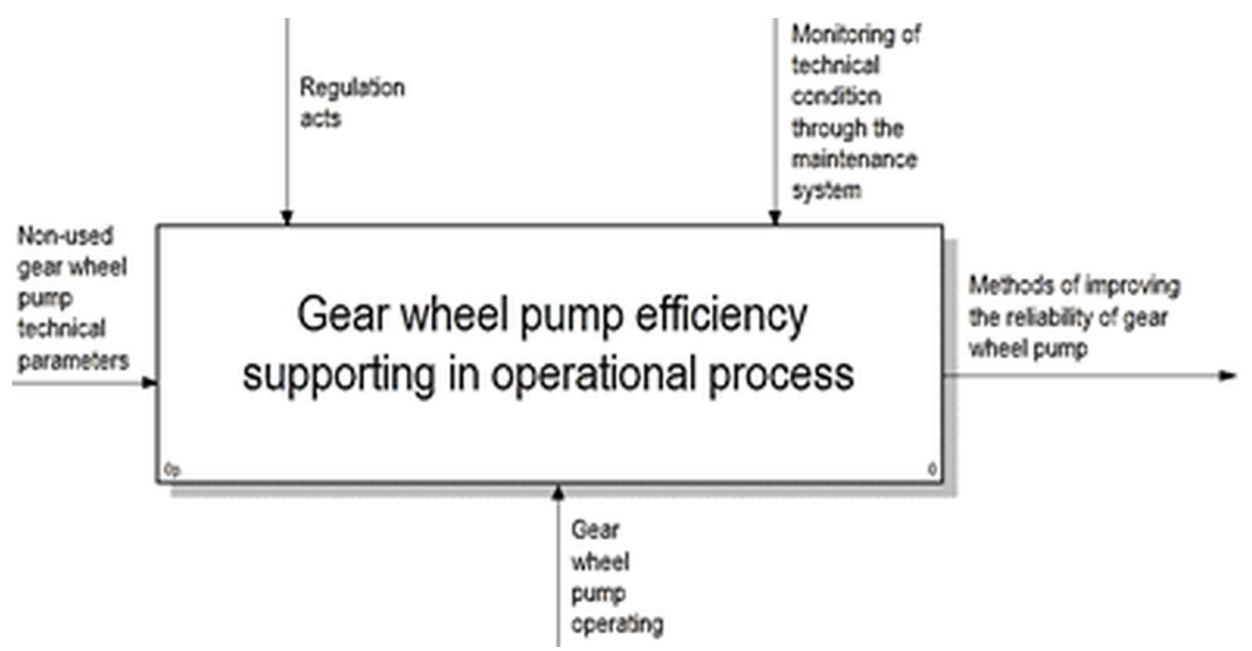

Fig. 1. Structural model "Gear wheel pump efficiency supporting in operational process".

As a resource, data on the parameters of not-used gear wheel pumps have been adopted, and the consumer can not influence on the quality of pumps production. Regulation acts and control of the technical condition of the gear wheel pump during operation through the maintenance system affect the main function through the level of personnel qualification. The final product is the development of methods for increasing the reliability of the operation of gear pumps. As the mechanisms for the performance of the function, the operation of gear wheel pumps is adopted.

After decomposition of the model, as shown in Figure 2, four main sub-functions were determined that affect the performance of a gear wheel pump:

- physical and chemical properties of working fluids;

- technical condition of the dump truck;

- operating conditions of the dump truck;

- environment.

As a result, after analyzing this structural model, it turned out that most of the parameters affecting all four sub-functions intersect, i.e. influence each to other and directly on the subfunctions themselves. It also turned out that the main parameters affecting the reliability of the hydraulic system of quarry dump trucks are kinematic viscosity. 


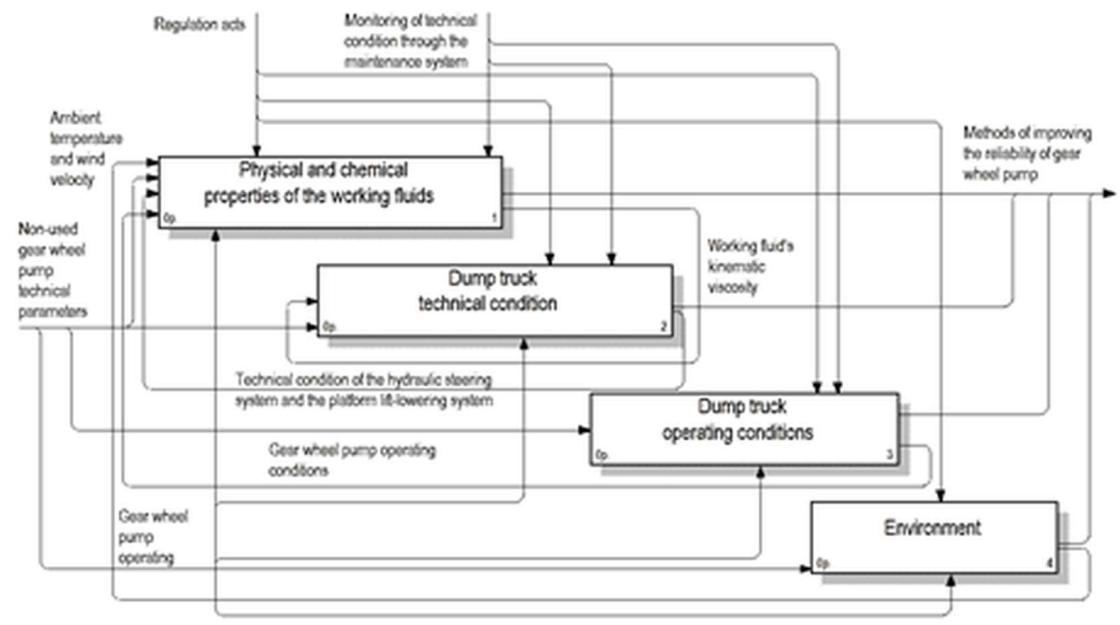

Fig. 2. Decomposition of the main sub-functions.

The kinematic viscosity depends on the stability of the working fluid to different temperatures: ambient temperature and operating temperature in the hydraulic system (Figure 3).

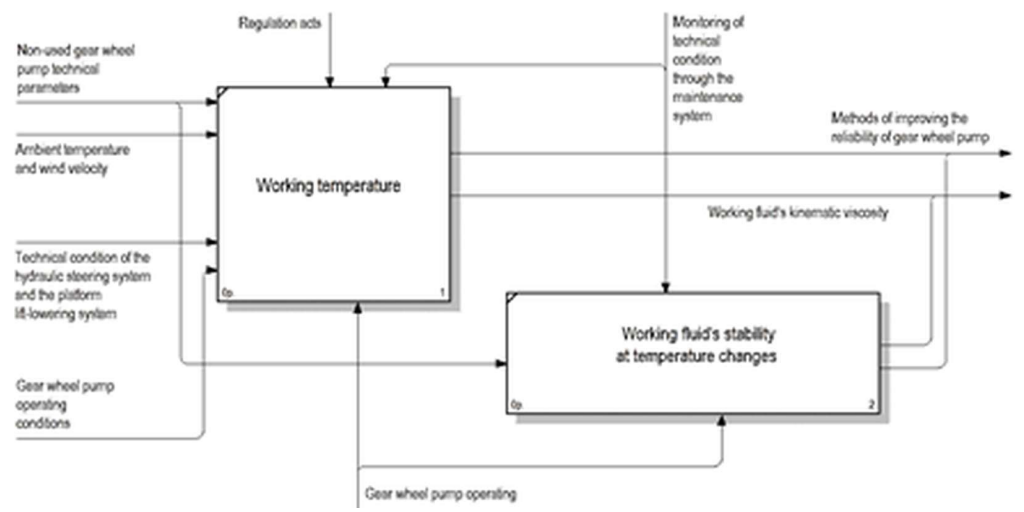

Fig. 3. Decomposition of the sub-function "Kinematic viscosity".

BelAZ dump trucks, which analyzed for the operating conditions of the hydraulic system, are operating in the Prokopyevsk-Kiselevsk coal area. In the hydraulic steering system and the platform lift-lowering system of the BelAZ dump trucks, three gear wheel pumps are used for the working fluid pumping. Mineral oils or their mixtures providing a nominal viscosity of 30-70 sq. mm per sec. and a minimum viscosity of 15 sq. mm per sec. are used as the working fluid in the hydraulic system of a dump truck with gear wheel pumps with an operating fluid temperature range from 0 to $80{ }^{\circ} \mathrm{C}[2,4]$.

At present, BelAZ dump trucks often use " $A$ " type hydraulic oil because of its relatively low cost. However, during the operation of BelAZ dump trucks in a wide range of ambient temperatures, the work is deteriorating up to the failure of the hydraulic steering system and the platform lift-lowering system. This is due to a changing of the oil's kinematic viscosity when the temperature is raised [5, 9-12].

According to TU 38.1011282-89 hydraulic oil of "A" type is recommended for winter operation. In the conditions of the Prokopyevsk-Kiselevsky coal region, the positive temperature stably keeps from May to September, reaching its maximum in July. 


\section{Results and Discussion}

Measurements of the temperature of the working fluid in the hydraulic system of the BelAZ dump trucks were carried out with the "Raytek MT6 Pyrometer" instrument. When carrying out field studies of temperature conditions of the hydraulic system of BelAZ dump trucks, the results presented in Figure 4 are obtained.

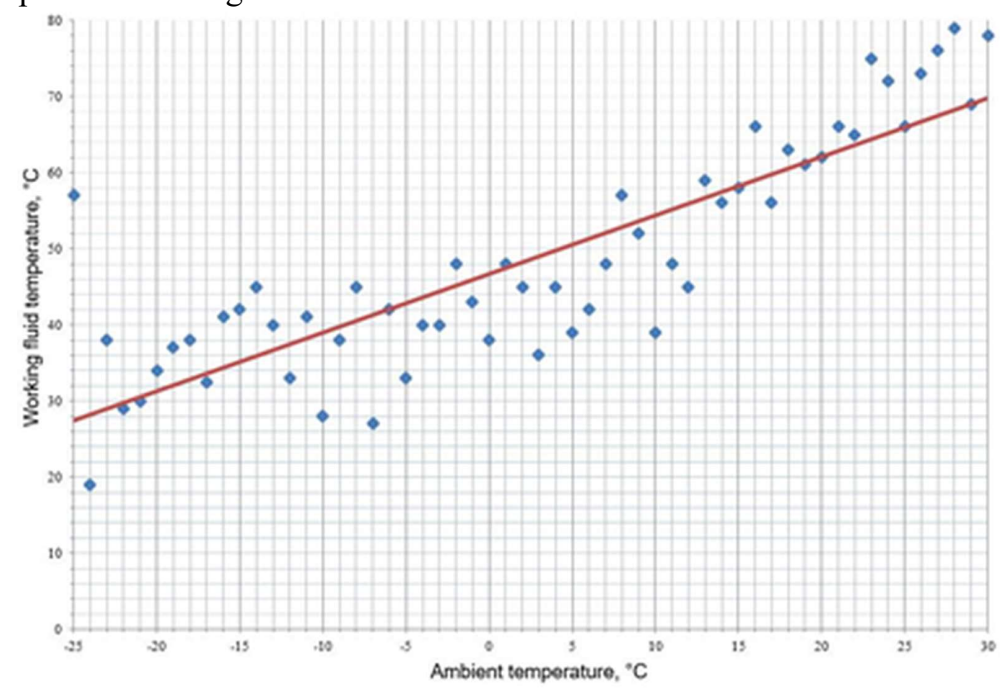

Fig. 4. Dependence of the temperature of the working fluid on the ambient temperature.

The conducted studies did not reveal a pronounced dependence of the change in the temperature of the working fluid in the hydraulic system of BelAZ dump trucks from the ambient temperature [13]. Consequently, the temperature of the working fluid depends, first of all, on the intensity of the dump truck, and the ambient temperature only affects the rate of heat exchange between the container and the working fluid and the environment. On the basis of previous studies, it is clear that the optimum viscosity of the working fluid is reached at temperatures from 48 to $68^{\circ} \mathrm{C}$.

\section{Conclusion}

From the above, it can be concluded that the A grade oil, positioned as "winter", should not be used at ambient temperatures below $-5{ }^{\circ} \mathrm{C}$ without diluting components, and at temperatures above $+20^{\circ} \mathrm{C}$ - without thickening components. However, the use of a multicomponent working fluid leads to an increase in the labor intensity of seasonal maintenance of dump trucks $[14,15]$. Consequently, further works on the stabilization of the parameters of the working fluid is advisable to lead in the direction of stabilizing its temperature.

\section{References}

1. N. Akhtar, Q. Adnan, M. Ahmad, M. Mehmoo, K. Farzana, J. Chem. Soc. Pak., 31:2, 201 (2009)

2. O. O. Fasina, H. Hallman, C.Schmidt, C. Clements, J. Am. Oil. Chem. Soc., 83, 899 (2006)

3. S. G. E. Giap, Journal of Physical Science, 21:1, 29 (2010) 
4. I. Stanciu, M. Leca, Buletin UPG - Seria Tehnică, LIX, 65 (2007)

5. M. T. Devlin, J. Senn, Lю Turner, T. Milner, J. Jao, Lubrication Sci., 18, 7 (2005)

6. O. Carmody, R. Frost, Y. Xi, S. Kokot, Journal of Colloid and Interface Science, 305:1, 17 (2007)

7. D. Knežević, V. Savić, Facta Universitatis Series: Mechanical Engineering, 4:1, 27 (2006)

8. S. H. Yoon, S. H. Park, C. S. Lee, Energy \& Fuels, 22, 652 (2008)

9. C. M. Fernandes, P. M. Amaro, R. C. Martins, J. H. Seabra, Tribology International, 66, 194 (2013)

10. A. Jukic, E. Vidovic, Z. Janovic, Chemistry and Technology of Fuels and Oils, 43:5, 386 (2007)

11. A. A. Azim, A. M. Nasser, N. S. Ahmed, E. Kafrawy, R. S. Kamal, Petroleum Science and Technology, 27:1, 20 (2009)

12. A. M.Nasser, Pet. Sci. Technol., 26, 514 (2008)

13. R. Gaikwad, P. Swamy, Acta. Chim. Slov, 55, 683 (2008)

14. Gylling, H., J. Allergy, 61, 895 (2006)

15. J. Fan, M. Müller, T. Stöhr, H. A. Spikes, Tribology Letters, 28:3, 287 (2007)

16. B. L. Gerike, V. I. Klishin, P. B. Gerike, A. A. Mokrushev, Journal of Mining and Geotechnical Engineering, 1, 19-34 (2018) DOI: 10.26730/2618-7434-2018-1-19-34

17. V. V. Aksenov, V. Yu. Sadovets, D. A. Pashkov, Journal of Mining and Geotechnical Engineering, 1, 11-18 (2018) DOI: 10.26730/2618-7434-2018-1-11-18 